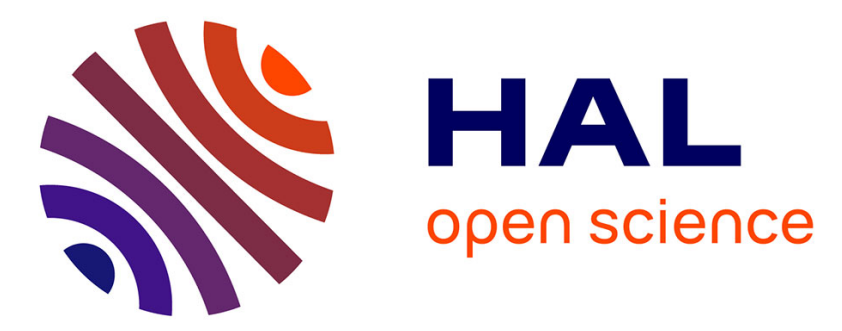

\title{
Ionic aggregation-induced emission dye with bulky counterions for preparation of bright near-infrared polymeric nanoparticles
}

Nagappanpillai Adarsh, Andrey Klymchenko

\section{- To cite this version:}

Nagappanpillai Adarsh, Andrey Klymchenko. Ionic aggregation-induced emission dye with bulky counterions for preparation of bright near-infrared polymeric nanoparticles. Nanoscale, 2019, 11 (29), pp.13977-13987. 10.1039/C9NR04085D . hal-02383709

\author{
HAL Id: hal-02383709 \\ https://hal.science/hal-02383709
}

Submitted on 5 Feb 2020

HAL is a multi-disciplinary open access archive for the deposit and dissemination of scientific research documents, whether they are published or not. The documents may come from teaching and research institutions in France or abroad, or from public or private research centers.
L'archive ouverte pluridisciplinaire HAL, est destinée au dépôt et à la diffusion de documents scientifiques de niveau recherche, publiés ou non, émanant des établissements d'enseignement et de recherche français ou étrangers, des laboratoires publics ou privés. 


\title{
Ionic Aggregation-Induced Emission Dye with Bulky Counterions for Preparation of Bright Near-Infrared Polymeric Nanoparticles
}

Received 00th January 20xx, Accepted 00th January 20xx

DOI: $10.1039 / x 0 x x 00000 x$

\begin{abstract}
Nagappanpillai Adarsh and Andrey S. Klymchenko*
Dyes exhibiting aggregation-induced emission (AIE) are attractive building blocks for preparation of bright fluorescent nanomaterials. AlEgens are especially efficient in pure dye aggregates, whereas they are much less explored as dopants in NPs build of hydrophobic polymers. Here, we describe an approach that combines cationic AlEgens with bulky hydrophobic counterions (fluorinated tetraphenylborates), that enables preparation of small and bright AIEgen-loaded polymeric NPs. To this end, we synthesised a cationic tetraphenylethylene (TPE) derivative and studied its salts with counterions of different size and hydrophobicity. In organic solvent/water mixtures all these salts exhibited typical AIE behaviour, whereas only salts with bulky hydrophobic counterions exhibited strongly redshifted emission in the near-infrared (NIR) region. Encapsulation of these salts into poly(methyl methacrylate-co-methacrylic acid) (PMMA-MA) NPs revealed that bulky counterions ensure (i) formation of small ( $50 \mathrm{~nm}$ ) AlEgen-loaded polymeric NPs; (ii) good fluorescence quantum yield (up to $30 \%$ ); and (iii) NIR emission reaching $700 \mathrm{~nm}$. By contrast, AIEgens with small inorganic anions (perchlorate and hexafluorophosphate) blended with PMMA-MA produced large aggregates with emission in the far-red region. Single-particle microscopy revealed that our 50-nm AIEgen-loaded PMMA-MA NPs were 6-fold brighter than the NIR emitting quantum dots (QD705). These NPs feature low cytotoxicity and compatibility with live cell imaging, in contrast to large aggregates of AlEgens with small inorganic counterions that failed to internalize into the cells. The present work shows that combination of cationic AIEgens with bulky counterions opens new routes for preparation of bright polymer-based nanomaterials.
\end{abstract}

\section{Introduction}

Fluorescent nanoparticles (NPs) play a crucial role in biological and biomedical research, since they have the potential to overcome the limitations of common fluorescent dyes, such as brightness and photostability. ${ }^{1-6}$ Their use in the field of bioimaging requires the optimal size, biocompatibility, and their surface chemistry. ${ }^{7-9}$ The extensively explored direction in fluorescent NPs field is inorganic NPs such as quantum dots $(Q D s)^{10,11}$ metal clusters ${ }^{12,13}$, dye-doped silica NPs ${ }^{14-16}$, and upconverting NPs. ${ }^{17-20}$ However, they lack flexibility for encapsulation of active molecules and to make them biocompatible, they should be coated with an organic shell. ${ }^{21-23}$ In addition, these nanoparticles always raised concerns for their long term toxicity and lack of biodegradability. ${ }^{24-28}$ Therefore, last decade have seen a dramatic growth of research on fully organic NPs based on dye molecules and their encapsulation into organic nanomaterials. ${ }^{29-33}$ The most representative examples are conjugated polymer NPs, ${ }^{34-37}$ dye-loaded lipid ${ }^{38,39}$ and polymer ${ }^{31,32}$ NPs, as well as NPs formed purely from organic

\footnotetext{
a. Laboratoire de Bioimagerie et Pathologies, UMR 7021 CNRS, Faculté de Pharmacie, Université de Strasbourg, Strasbourg CS 60024, France Email: andrey.klymchenko@unistra.fr
}

Electronic Supplementary Information (ESI) available: Additional spectroscopic and microscopic experiments. See DOI: 10.1039/x0xx00000x dyes, ${ }^{33,40,41}$ especially aggregation-induced emission (AIE) dyes. ${ }^{31,42,43}$

The dye-loaded polymeric NPs gained popularity over recent years ${ }^{31,32}$ due to their exceptional brightness, ${ }^{44,45}$ capacity to encapsulate different dyes, ${ }^{46,47}$ tuneable size ${ }^{48,49}$ and available surface chemistry. ${ }^{50}$ The major challenge in conventional dye loaded nanoparticle is the aggregation-caused quenching (ACQ) observed when a large number of dyes aggregated in a small and confined volume. ${ }^{32,51-55}$ Several solutions were proposed in literature to prevent the self-quenching through an appropriate fluorophore design. ${ }^{32}$ One of them is to tailor bulky groups to the fluorophore, so that it can prevent the aggregation. ${ }^{56-59}$ However, tedious molecular design and synthesis is required to retain the properties of the fluorophores after modification.

Another important approach to resolve the problem of ACQ is the aggregation induced emission (AIE) introduced by Tang and co-workers. ${ }^{60}$ The reason behind the AIE phenomenon was identified to be a specific dye packing and the restriction of intramolecular motion (RIM) of the molecules. ${ }^{42,43}$ Development of AIE luminogens (AIEgens) with twisted conformation attracted immense attention due to their ability to prevent the traditional ACQ process and for their higher brightness and increased photostability. ${ }^{61-65}$ Tetraphenylethene (TPE), a propeller-shaped conjugated molecule, is one of the most efficient AIE luminogens which is facile for the chemical modifications, while preserving their photophysical properties. ${ }^{66-69}$ To make these dyes compatible in biological media, AIEgens were either polymerized in the form of NPs or coated with different stabilizing agents based on amphiphilic 
lipids (e.g. DSPE-PEG) or polymers. ${ }^{70-73}$ On the other hand, encapsulation of AlEgens into solid matrixes of common biocompatible/biodegradable polymers, such as poly(lactic-coclycolic acid (PLGA) or poly(methyl methacrylate-co-methacrylic acid (PMMA), requires controlled excentric loading of fluorogen, because their homogeneously dispersed state (as individual molecules) in the matrix is less emissive than in the aggregated state. ${ }^{74}$

Recently, we proposed to use bulky hydrophobic counterions to ensure efficient encapsulation of cationic dyes with minimized self-quenching. ${ }^{75}$ These bulky counterions function as spacers between the individual cationic dye molecules inside the nanoparticle matrices. Using bulky fluorinated tetraphenylborates, we previously succeed to synthesize the dye-loaded polymeric NPs with excellent brightness, biocompatibility and biodegradability, which surpassed many-fold the QDs of respective size.44-48 The counterion approach was found to be compatible with both rhodamines ${ }^{75}$ and cyanine ${ }^{47}$ and it works in different polymeric matrices. ${ }^{45}$ Moreover, the approach was extended to different classes of counterions: fluorinated tetraphenylborates and aluminates ${ }^{76}$ as well as bulky borohydrides. ${ }^{77}$ The counterion also ensures close proximity of dyes in the polymer matrix, which favors dye-dye communication. ${ }^{75}$ The latter enables preparation of giant light-harvesting nanoantennas, in which thousands of donor molecules efficiently transfer the excitation energy to a single cyanine molecule inside the particle and thus amplify their emission to ca. $>1000-$ fold. ${ }^{44}$ The latter phenomenon has already been applied for biosensing, where
DNA-functionalized nanoantennas, 100-fold brighter than corresponding QDs, enabled amplified detection of nucleic acids. ${ }^{50}$

We hypothesized that the counterion approach can be combined with AlEgens in order to prepare bright dye-loaded polymer NPs. Recent work in Tang's group showed an example of cationic NIR emitting TPE-based AIEgen, which required special surfactant bearing aromatic coronene residue as protective shell in order to exhibit good fluorescence quantum yield and stability in biological media. ${ }^{78}$ In the present work, we designed an analogous cationic AlEgen and studied the capacity of bulky counterions to improve its emission properties in aqueous media and inside polymeric NPs. In organic solvent/water mixtures all studied salts showed typical AIE behaviour, whereas their blended NPs with hydrophobic poly(methyl methacrylate-co-methacrylic acid) (PMMA-MA) revealed dramatic role of the counterion. Indeed, it was found that bulky hydrophobic counterions (fluorinatedtetraphenyl borates) are essential to obtain small ( $50 \mathrm{~nm}$ ) AlEgen-loaded NPs results with good fluorescence quantum yield and nearinfrared emission. Single-particle microscopy showed that these particles are highly photostable and 6-fold brighter than corresponding NIR QDs (QD705). NPs loaded with AlEgen/bulky counterion were low-toxic and compatible with cellular imaging applications, which was not the case of large aggregates formed by AlEgens with small inorganic anions. In short, by incorporating bulky counterions to an AIE active TPE chromophore, we developed a unique strategy to prepare bright polymeric NPs for biological applications.
A)
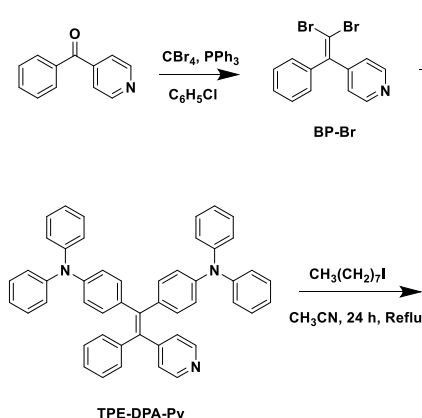

B)

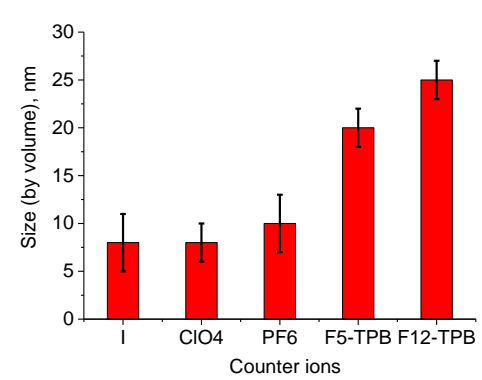

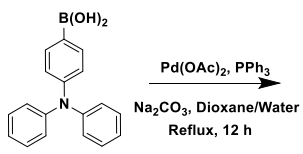

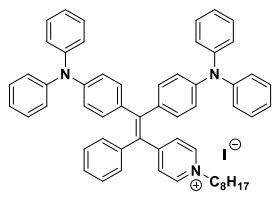

TPE-DPA-Py iodide

C)

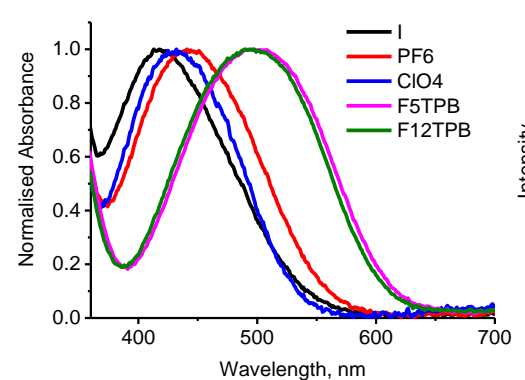

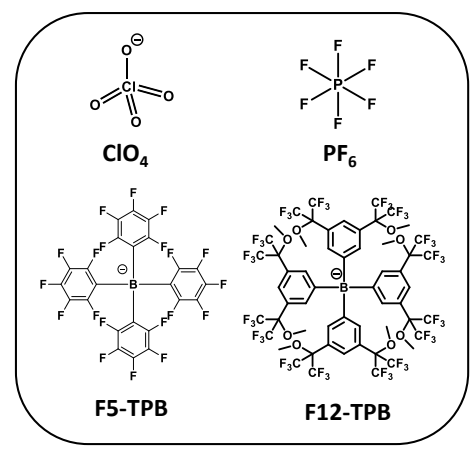

D)

Fig. 1. A) Synthetic route for TPE dye TPE-DPA-Py and different counterions used for the formulation of NPs. B) Size distribution of TPE NPs formed by ion association with different counterions through dynamic light scattering (DLS) measurements. C) Absorption spectra of TPE NPs (1 $\mu$ M) formed with different counterions. D) Fluorescence spectra of TPE NPs $(1 \mu \mathrm{M})$ formed with different counterions. The spectra were normalized to the same absorbance at the excitation wavelength (450 $\mathrm{nm}$ ). 


\section{Result and Discussion}

\section{Synthesis and characterization of TPE derivatives.}

By following the report of Tang and co-workers ${ }^{78}$ to extend the emission spectrum of TPE derivatives to NIR range, we designed an analogous AIEgen, TPE-DPA-Py, bearing two electron-donating diphenylamine groups and one electronwithdrawing 1-octylpyridinium. Frist, TPE-DPA-Py iodide was synthesized in three steps starting from 4-benzoyl pyridine (Fig. $1 \mathrm{~A})$. $\mathrm{BP}-\mathrm{Br}$ was obtained in $\mathrm{ca}$. $60 \%$ yield by the reaction between 4-benzoyl pyridine with carbon tetrabromide and triphenyl phosphine, which was subsequently reacted with (4(diphenylamino)phenyl)boronic acid to yield the parent TPEDPA-Py derivative in $c a$. $60 \%$ yield. Alkylation of TPE-DPA-Py with 1-octyliodide yields the target TPE-DPA-Py iodide in $80 \%$ yield (Fig. 1A). Anion exchange reaction with corresponding potassium or sodium salts (hexafluorophosphate $\left(\mathbf{P F}_{6}\right)$, perchlorate $\left(\mathrm{ClO}_{4}\right)$, tetrakis(pentafluorophenyl)borate ethyl etherate (F5-TPB) and tetrakis[3,5-bis-(1,1,1,3,3,3-hexafluoro2-methoxy-2-propyl) phenyl]borate (F12-TPB)) gave with quantitative yield the corresponding TPE-DPA-Py salts with different counterions, named respectively TPE-CIO4, TPE-PF6, TPE-F5 and TPE-F12. All intermediates and products were unambiguously characterized by NMR and mass spectroscopy (see Experimental section).
A)
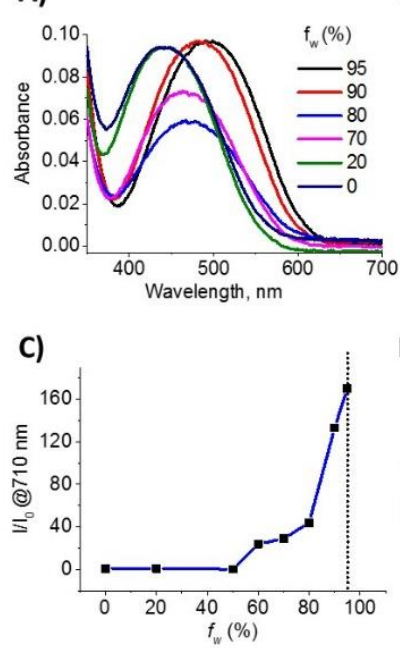

B)
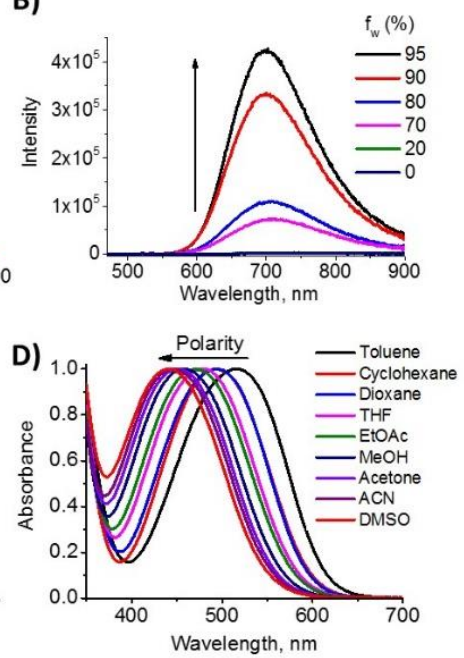

Fig. 2. AIE characteristics of TPE-F12. A) Absorption and B) Fluorescence spectra of TPEF12 in $\mathrm{CH}_{3} \mathrm{CN}-\mathrm{H}_{2} \mathrm{O}$ mixtures with different water fractions $(\mathrm{fw})$. C) Plot of the relative fluorescence intensity $\left(\mathrm{I} / \mathrm{I}_{0}\right)$ at $710 \mathrm{~nm}$ versus $\mathrm{fW}$ of the $\mathrm{CH}_{3} \mathrm{CN}-\mathrm{H}_{2} \mathrm{O}$ mixture of TPE-F12. Excitation wavelength: $450 \mathrm{~nm}$. D) Absorption spectra of TPE-F12 in solvents having different polarities, showing negative solvatochromism.

Initially, we examined the ability of the apolar cationic TPEDPA-Py to form NPs with different counterions (Fig. 1A) by ionassociation. ${ }^{79-85}$ For this, we mixed TPE-DPA-Py iodide $(2 \mu \mathrm{M})$ with a 10-fold molar excess of the corresponding counterions in water. Dynamic light scattering (DLS) measurements showed that TPE-DPA-Py iodide in the presence of counterions forms relatively small particles ranging from $c a .6-30 \mathrm{~nm}$, dependent on the size of the counterions (Fig. 1B). In the presence of the bulky fluorinated TPB counterion (F5-TPB and F12-TPB), we observed ca. 60-80 $\mathrm{nm}$ red shift in absorption with $\sim 3$-fold enhanced fluorescence compared to the NPs formed with smaller counterions such as PF6 and ClO4 (Fig. 1C and 1D). These results show that counterions can tune aggregation behaviour of TPE-DPA-Py, and the bulky ones can improve optical properties of these aggregates.

\section{AIE behaviour of TPE-DPA-Py with different counterions}

Aggregation behaviour of TPE-F5 and TPE-F12 was further studied in different water-acetonitrile mixtures. These dyes are soluble in neat acetonitrile, whereas addition of water to acetonitrile resulted in the formation of dye aggregates, observed as large particles (>100 nm) by DLS (Table S1). Both dye salts showed an absorption maximum at $440 \mathrm{~nm}$ in neat acetonitrile and negligible fluorescence due to the strong intramolecular rotation of the aryl rings (Fig. 2A-B and S1). Upon increasing the water fraction in acetonitrile $\left(f_{W}\right)$ from 0 to $95 \%$, the absorption spectra shifted towards longer wavelength region by $c a .60 \mathrm{~nm}$. The red shift in the absorption spectra of TPE-DPA-Py can be attributed to the strong negative solvatochromism exhibited by the dye (Fig. 2D). Indeed, aggregation of F12-TPB or F5-TPB in water should lead to drop of environment polarity of the dye within the aggregate, which in turn shifts its absorption to the red. The fluorescence intensity remained low up to $50 \%$ of water fraction, whereas further increase in water fraction led to ca. 180-fold enhancement in the emission of the dye salt (Fig. 2C, S1). Thus, both TPE-F5 and TPE-F12 exhibited typical AIE behaviour, in line with other AlEgens reported earlier. ${ }^{43,78,82}$ Remarkably, the emission maximum of TPE-F5 and TPE-F12 in water reached NIR region $\sim 700 \mathrm{~nm}$. On the other hand, the AIE experiments using dye salts with smaller counterions (TPE-PF6 and TPE-CIO4) also showed AIE behaviour, and their fluorescence quantum yields at $80 \%$ water were even higher than those with bulky anions. The latter can be explained by probably tighter packing of the AlEgen in the aggregates, thus minimizing the non-radiative deactivation due to the intramolecular rotation. However, above $80 \%$ of water the fluorescence intensity decreased significantly (Fig. S2,S3). The latter is observed in some AIEgens, which is probably related to a TICT-based quenching at high water concentrations. ${ }^{43,78,86}$ Moreover, the emission maxima of TPE-PF6 and TPE-ClO4 were centred in the far-red region around $650 \mathrm{~nm}$, in contrast to NIR emitting salts with bulky counterions. The observed $50 \mathrm{~nm}$ red shift for AIEgen with bulky counterions is probably related to much larger dimeter of TPEF5 and TPE-F12, 1.16 and $1.60 \mathrm{~nm}$, respectively, in comparison to $\mathbf{P F}_{6}$ and $\mathrm{ClO}_{4}, 0.33$ and $0.35 \mathrm{~nm}$, respectively, which can induce larger dye-dye distance in case of bulky counterions. It should be noted that the dye salts with these counterions are amorphous materials, sometimes called as frozen ionic liquids, ${ }^{80,83,84}$ which do not allow X-ray crystallography. Therefore, better understanding of the counterion effect will require a dedicated theoretical study. 

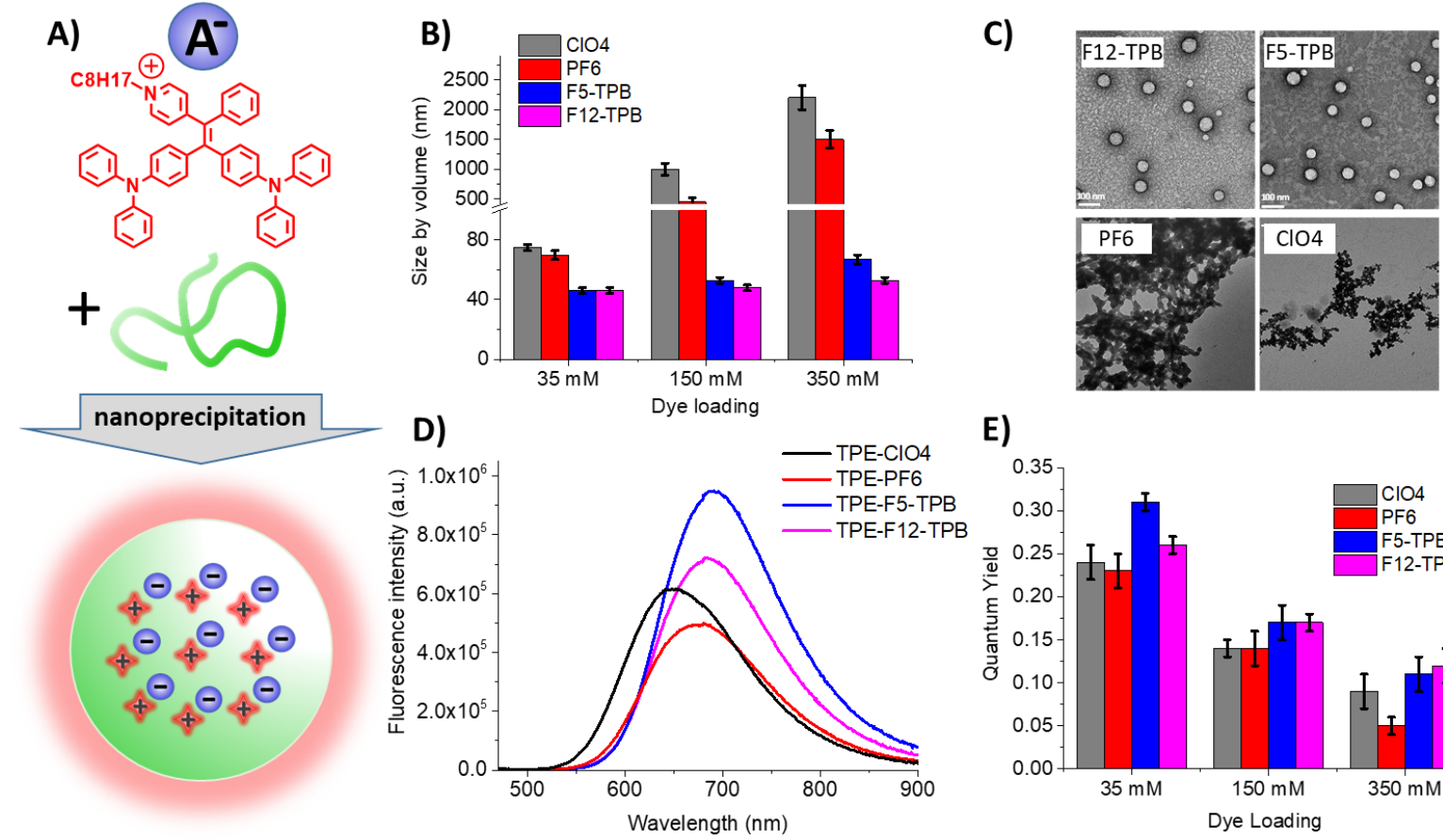

E)

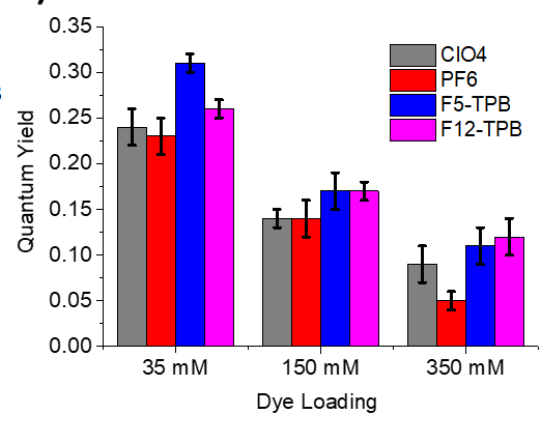

Fig. 3. Photophysical characterization of TPE-loaded PMMA-MA NPs. A) Schematic presentation of TPE-loaded PMMA-MA NPs. B) Plot showing the size by volume (dynamic light scattering) of polymeric NPs loaded with salts of AIEgen with different counterions at varied concentration with respect to the polymer. C) TEM images of the different TPE polymeric NPs (PMMA-MA, 350 mM, pH 7.4, counter stained with uranyl acetate). Scale bar: $100 \mathrm{~nm}$. D) Fluorescence spectra of PMMA-MA NPs loaded with different AIEgen-counterion salts at the highest concentration ( $350 \mathrm{mM}$ ). Excitation wavelength: $450 \mathrm{~nm}$. E) Dependence of fluorescence quantum yield with regard to the loading of different TPE-couterion salts in polymeric NPs.

\section{AlEgen-loaded polymeric nanoparticles}

Following the encouraging results on AIEgen salts with bulky counterions, we further studied their encapsulation into NPs formed by a biocompatible polymer PMMA-MA (Fig. 3A). We used our recently developed protocol of charge-controlled nanoprecipitation, ${ }^{48}$ wherein the acetonitrile solution of PMMA-MA and a dye salt dissolved in organic solvent (acetonitrile) were rapidly added into aqueous medium $(\mathrm{pH}$ 7.4). We have formulated the polymeric NPs at different dye concentrations with respect to the polymer $(35 \mathrm{mM}, 150 \mathrm{mM}$ and $350 \mathrm{mM}$ ) for the TPE dye with different counterions (TPEClO4, TPE-PF6, TPE-F5 and TPE-F12). DLS measurements suggested that the dyes, TPE-F5 and TPE-F12 formed small NPs (ca. 45-60 nm) even at very high loadings indicating minimal influence of the dye salt on the particle size. By contrast, encapsulation of the TPE derivatives with smaller counterions such as TPE-CIO4 and TPE-PF6 led to a large increase in the NP size with the increase in the dye loading (Fig. 3B). Transmission Emission Microscopy (TEM) measurements supported DLS data, showing uniform spherical particles of 48-50 nm size for TPE-F5 and TPE-F12 at $350 \mathrm{mM}$ dye loading, but large aggregates for TPE-CIO4 and TPE-PF6 (Table 1). These results indicate the importance of the bulky counterions for the preparation of small monodisperse polymeric NPs (Fig. 3C). According to our earlier studies ${ }^{75-77}$, bulky counterions render dye salt highly stable and hydrophobic, preventing ion exchange with the aqueous medium and the negatively charged carboxylates of a polymer, which ensures dye encapsulation inside the hydrophobic core of NPs without their adsorption to the NP surface. On the other hand, cationic AlEgens with small hydrophilic counterions probably dissociates in water and then adsorb at the negatively charged NPs surface leading to the observed particle aggregation (Fig. 3C).

NPs loaded with TPE-F5 and TPE-F12 salts exhibited higher fluorescence quantum yields and red shifted emission compared to the salts with small counterions (Fig. 3D,E). These results are in line with the data for NPs prepared by the ionassociation method (Fig. 1). For all AlEgen dye salts, increase in the dye loading 10-fold (from 35 till $350 \mathrm{mM}$ ) decreased the fluorescence quantum yield by 2-2.5 fold, probably because of some ACQ effect. The presence of bulky counterions decreased this ACQ effect, showing that these type of counterion can minimize ACQ of AlEgens in polymer NPs. Moreover, we should stress that the bulky counterions shifted emission of the NPs to NIR region ( 700 $\mathrm{nm}$ ). As a result, TPE-F12 and TPE-F5 NPs showed a stock shift of $c a .250 \mathrm{~nm}$, which is much larger than the conventional NIR fluorophores (e.g. 30-40 nm for cyanine 5.5 and 7.5). ${ }^{38}$ The large Stokes shift is important for minimizing auto-fluorescence and light-scattering in bioimaging applications. To our knowledge, this is the first report showing that the counterions can control brightness and emission colour of NPs formed by typical AIEgens. 
A)
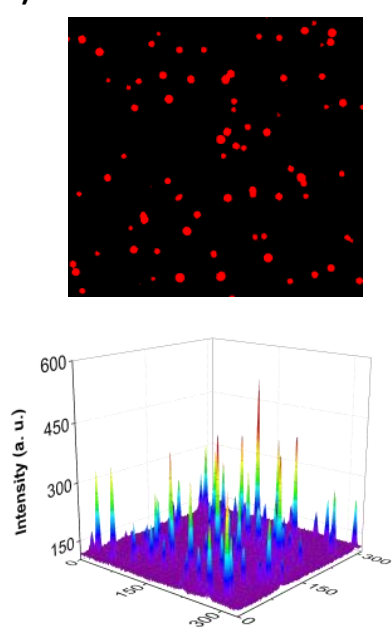

B)
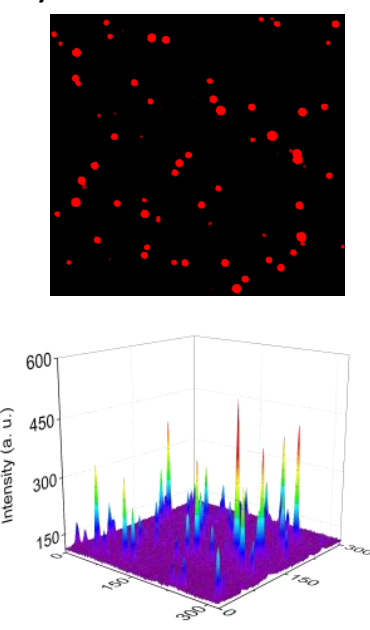

C)
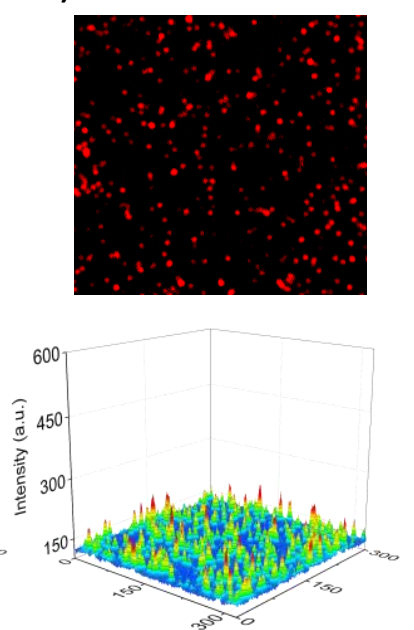

Fig. 4. Single-particle fluorescence of TPE-loaded polymeric NPs under wide field fluorescence microscopy. Single-particle fluorescence images (top) and the corresponding 3D representation (bottom) of A) TPE-F12 NPs; B) TPE-F5 NPs and C) QD705 after immobilizing the particles on glass plates.

Table 1. Summarized properties TPE dye salts in solutions and in form of NPs a

\begin{tabular}{|c|c|c|c|c|c|c|c|c|c|c|c|c|c|c|c|}
\hline \multirow[t]{3}{*}{ Dye Salts } & \multicolumn{3}{|c|}{$\lambda_{\mathrm{abs}, \mathrm{nm}}$} & \multicolumn{2}{|c|}{$\lambda_{\text {flu }}, \mathrm{nm}$} & \multicolumn{2}{|c|}{ Q.Y. } & \multicolumn{5}{|c|}{ Size } & \multirow{3}{*}{$\begin{array}{c}\text { Dyes/ } \\
\text { NPc }\end{array}$} & \multicolumn{2}{|c|}{ Brightness $^{c}$} \\
\hline & \multirow{2}{*}{$\begin{array}{c}\text { In } \\
\text { ACN }\end{array}$} & \multirow{2}{*}{$\begin{array}{l}\text { Bare } \\
\text { NPs }^{b}\end{array}$} & \multirow{2}{*}{$\begin{array}{c}\text { PMMA } \\
\text { NPs }^{c}\end{array}$} & \multirow{2}{*}{$\begin{array}{l}\text { Bare } \\
\text { NPs }\end{array}$} & \multirow{2}{*}{$\begin{array}{c}\text { PMMA } \\
\text { NPs }^{c}\end{array}$} & \multirow{2}{*}{$\begin{array}{l}\text { Bare } \\
\text { NPs }^{b}\end{array}$} & \multirow{2}{*}{$\begin{array}{l}\text { PMMA } \\
\text { NPs }^{c}\end{array}$} & \multicolumn{4}{|c|}{ DLS } & \multirow{2}{*}{$\begin{array}{l}\text { TEM } \\
\text { NPs }^{c}\end{array}$} & & \multirow{2}{*}{$\begin{array}{c}\text { Theore } \\
\text { tical }\end{array}$} & \multirow{2}{*}{$\begin{array}{c}\text { Expe } \\
\text { rime } \\
\text { ntal }\end{array}$} \\
\hline & & & & & & & & $\begin{array}{l}\text { Bare } \\
\text { NPs }^{b}\end{array}$ & PDI & $\begin{array}{c}\text { PMMA } \\
\text { NPs }^{c}\end{array}$ & PDI & & & & \\
\hline TPE-F12 & 445 & 510 & 480 & 700 & 685 & $\begin{array}{c}0.09 \\
\pm 0.01\end{array}$ & $\begin{array}{c}0.12 \\
\pm 0.02\end{array}$ & $\begin{array}{c}168 \\
\pm 2\end{array}$ & 0.10 & $53 \pm 2$ & 0.12 & $48 \pm 2$ & 12219 & $\begin{array}{l}2.05 \\
\times 10^{7}\end{array}$ & $\begin{array}{l}1.76 \\
\times 10^{7}\end{array}$ \\
\hline TPE-F5 & 445 & 515 & 472 & 716 & 690 & $\begin{array}{c}0.07 \\
\pm 0.02\end{array}$ & $\begin{array}{c}0.11 \pm \\
0.01\end{array}$ & $\begin{array}{l}175 \\
\pm 2\end{array}$ & 0.08 & $67 \pm 3$ & 0.10 & $50 \pm 2$ & 13497 & $\begin{array}{l}2.67 \\
\times 10^{7}\end{array}$ & $\begin{array}{r}2.52 \\
\times 10^{7}\end{array}$ \\
\hline TPE-PF6 & 448 & 430 & 450 & 638 & 670 & $\begin{array}{c}0.22 \\
\pm 0.03\end{array}$ & $\begin{array}{c}0.05 \pm \\
0.02\end{array}$ & $\begin{array}{c}600 \\
\pm 100\end{array}$ & 0.95 & $\begin{array}{c}1500 \pm \\
150\end{array}$ & 0.42 & $d$ & $d$ & d & d \\
\hline TPE-CIO4 & 445 & 450 & 440 & 630 & 645 & $\begin{array}{c}0.24 \\
\pm 0.02\end{array}$ & $\begin{array}{c}0.09 \pm \\
0.02\end{array}$ & $\begin{array}{l}500 \\
\pm 75\end{array}$ & 0.34 & $\begin{array}{c}2200 \pm \\
200\end{array}$ & 0.38 & d & $d$ & d & d \\
\hline
\end{tabular}

a Errors are standard deviation of the means $(n=3)$. b NPs formed without PMMA-MA. cPMMA-MA NPs loaded with 350 mM of corresponding TPE-counterion salts. ${ }^{\mathrm{d}}$ Not determined due to the formation of large aggregates.

\section{Single-particle brightness}

The single-particle brightness of the TPE NPs was determined using wide-field fluorescence microscopy. For this, the diluted (2000-fold) polymeric TPE NPs were immobilized on a glass surface and imaged under microscope upon excitation at $470 \mathrm{~nm}$ and emission collected at 670-740 nm. TPE-F5 and TPEF12 NPs appeared as bright fluorescent spots, whereas with TPE-CIO4 and TPE-PF6, large aggregates were observed (Fig. S4). Interestingly, the brightness of TPE-F5 was found to be 6fold higher compared to the QDs of similar emission wavelength (QD705) (Fig. 4). The theoretical brightness, expressed as $\mathrm{N}$ (number of dyes) $\times \varepsilon$ (molar absorptivity) $\times \phi$ (quantum yield), for TPE-F5 NPs was calculated to be $2.7 \times 10^{7} \mathrm{M}^{-1} \mathrm{~cm}^{-1}$, whereas for QD705 at $470 \mathrm{~nm}$ it was found to be $4.2 \times 10^{6} \mathrm{M}^{-1} \mathrm{~cm}^{-1}$ (determined from absorption spectra and the available data from the provider, ThermoFisher Scientific). Thus, the theoretical difference in the single-particle brightness between TPE-F5 NPs and DQ705 (6.4-fold) is in close agreement with the experimental values. Video-rate imaging of TPE NPs under the continuous irradiation with a strong excitation power $(7.6 \mathrm{~W}$ $\mathrm{cm}^{-2}$ ) revealed their good photostability and absence of blinking (Fig. S5, ESI). The latter is in contrast to QDs (see Supporting video for QD705) ${ }^{10,11}$ and polymeric NPs loaded with salts of a rhodamine dye and a bulky counterion, ${ }^{75}$ which typically show whole-particle blinking.

\section{Cellular imaging applications}

First, we verified stability of our NPs in biological media. The fluorescence spectra of polymeric NPs encapsulated with TPEF5 and TPE-F12 before and after incubation with 10\% Foetal Bovine Serum (FBS) in pH 7.4 buffer for $1 \mathrm{~h}$ remains the same with negligible changes in the intensity, which indicates good stability of these NPs in the biological medium (Fig. S6, ESI). Further we examined the potential of our polymeric TPE NPs in cellular imaging applications. For this, we incubated the brightest polymeric NPs based on TPE-F5 and TPE-F12 (350 mM 
loading) with HeLa cells for $3 \mathrm{~h}$ and imaged the cells using fluorescence microscopy. As a control we also studied the polymeric NPs loaded with TPE-PF6. The cells were co-stained with a blue membrane marker (F2N12SM) ${ }^{87}$ for the clear visualization of the cell contour. After $3 \mathrm{~h}$ of incubation, the TPEF5 and TPE-F12 NPs showed efficient internalization and strong intracellular fluorescence in form of dots (Fig. 5) According to the previous studies this dotted emission corresponds to nanoparticles that entered the cells by endocytosis. ${ }^{75}$ By contrast, PMMA NPs loaded with TPE-PF6 appeared in form heterogeneous large fluorescent aggregates randomly distributed within the sample without any clear localization in cells. We have also incubated TPE-PF6 AlEgen NPs without polymer at similar concentrations. Again, large fluorescent aggregates without clear cellular localization were observed, as in the case of polymer NPs doped with TPE-PF 6 (Fig. S7, ESI). This result suggests that ionic AIEgens with small counterions form particles that readily aggregate in physiological conditions. The problem remains even when these salts are blended with
PMMA NPs, probably due to the poor encapsulation into polymer NPs, as it was shown in case of cationic dye based on rhodamine B. ${ }^{75}$ Then, we verified photostability of our NPs directly in cells by their continuous illumination in the wide-field microscope (Fig. S8). At the excitation power density $2.5 \mathrm{~W} \mathrm{~cm}^{-}$ 2 , the signal in the fluorescence images for all the three studied NPs did not show significant changes for at least 2 min (corresponding to 600 recorded image frames), indicating their good photostability. Finally, we checked cytotoxicity of the NPs using MTT assay (Fig. S9). Importantly, at the dye concentration used for imaging (210 nM), TPE-F5 and TPE-F12 NPs showed almost negligible cytotoxicity $(91 \pm 10$ and $90 \pm 10 \%$ cell viability, respectively), whereas TE-PF6 NPs were already cytotoxic (58 $\pm 8 \%$ cell viability). We can speculate that the lower cytotoxicity of NPs with bulky counterions is related to better encapsulation of their AlEgen salts, as discussed above. Thus, we showed that combination of an AIEgen with bulky hydrophobic counterions enables preparation of dye-loaded polymer NPs compatible with live cell imaging.
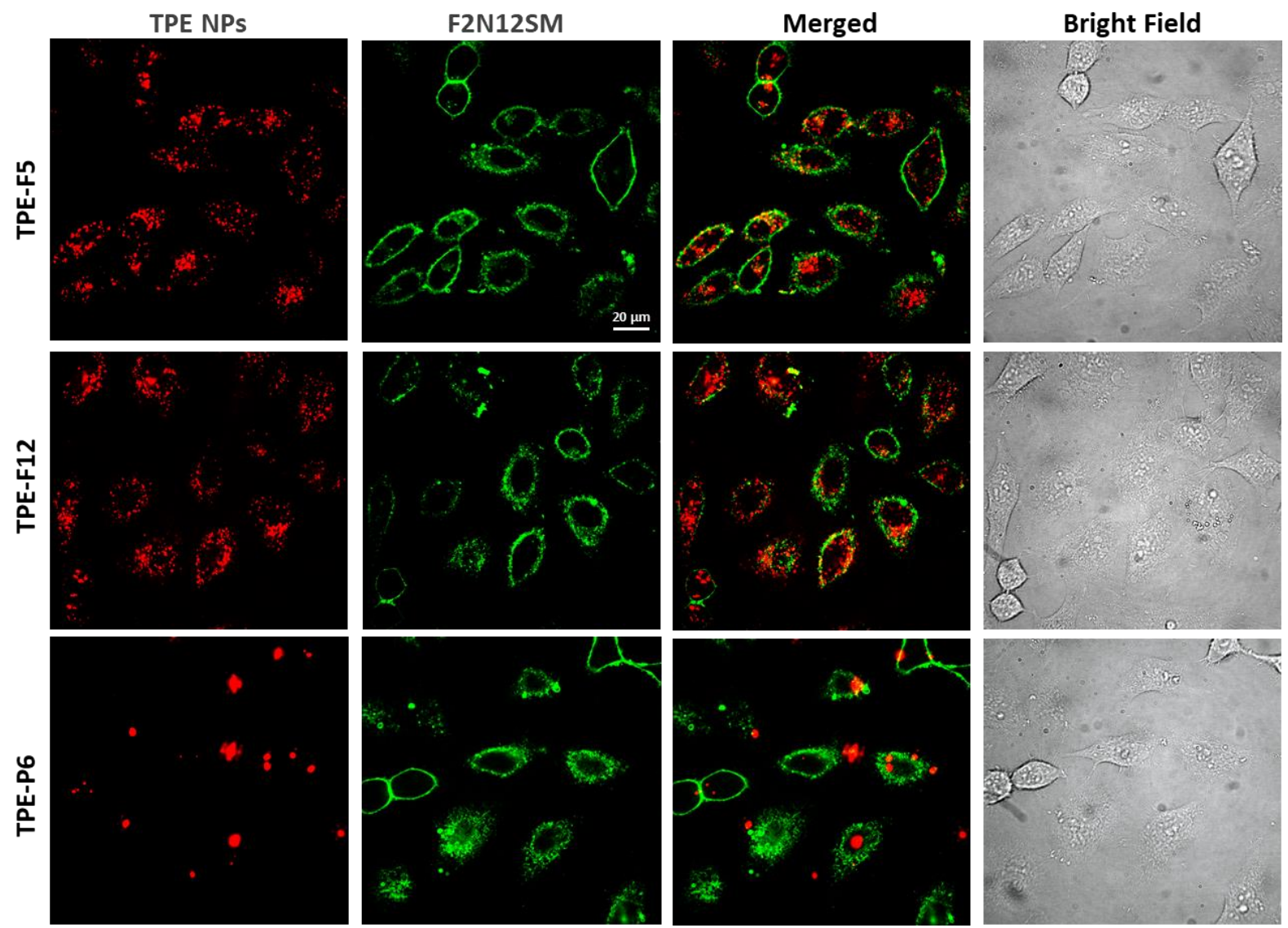

Fig. 5. Fluorescence imaging of TPE-loaded polymeric NPs in HeLa cells. The images correspond to NPs loaded with A) TPE-F5, B) TPE-F12 and C) TPE-PF 6 , which were incubated with HeLa cell lines for $3 \mathrm{~h}$ at $37^{\circ} \mathrm{C}$. The panels in green present images of co-staining with a membrane marker F2N12SM using an excitation at 405 nm and a detection range of $450-$ $500 \mathrm{~nm}$, while panels in red present images of TPE polymeric NPs with an excitation at $488 \mathrm{~nm}$ and a detection range of 670-750 nm. 


\section{Experimental}

Potassium tetrakis(pentafluorophenyl)borate ethyl etherate, tetrakis[3,5-bis-(1,1,1,3,3,3-hexafluoro-2-methoxy-2propyl)phenyl]borate ( $\geq 99.5 \%)$, acetonitrile, were purchased from Sigma-Aldrich and used as receive Milli-Q water (Millipore) was used in all experiments. Sodium phosphate monobasic (99.0\%, Sigma-Aldrich) and sodium phosphate dibasic dihydrate (99.0\%, Sigma-Aldrich) were used to prepare $20 \mathrm{mM}$ phosphate buffer solutions at $\mathrm{pH}$ 7.4. Modified Eagle's Medium (MEM), Dulbeco's Modified Eagle's Medium (DMEM), reduced serum medium (optiMEM), fetal bovine serum (FBS), phosphate buffered saline (PBS), L-Glutamine (100x), Penicillin and Streptomycin $(10000 \mathrm{U} / \mathrm{mL}$ were purchased from Fisher Scientific. NMR spectra of the synthesized TPE derivatives and intermediate products were recorded at $20^{\circ} \mathrm{C}$ on Bruker Avance III $500 \mathrm{MHz}$ spectrometer. Mass spectra were obtained using an Agilent Q-TOF 6520 mass spectrometer (Spectra are given in the ESI).

\section{Synthesis of TPE dyes}

Synthesis of 4-(2,2-dibromo-1-phenylvinyl)pyridine (BP- $\left.\mathrm{Br}_{2}\right)$. 4Benzoylpyridine (182 mg, $1.00 \mathrm{mmol}$ ) was dissolved in chlorobenzene $(50 \mathrm{~mL})$. Carbon tetrabromide $(662 \mathrm{mg}, 2.00$ $\mathrm{mmol}$ ) and PPh3 (1.05 g, $4.00 \mathrm{mmol}$ ) were added and the reaction mixture was heated to reflux and maintained for $3 \mathrm{~d}$. After this time the reaction mixture was allowed to cool to $\mathrm{rt}$ and insoluble material was removed by filtration. The filtrate was treated with $50 \mathrm{~mL}$ of $1 \mathrm{M}$ aq. $\mathrm{HCl}$. The aqueous layer was separated and basified with $1 \mathrm{M}$ aq. $\mathrm{NaOH}$ until $\mathrm{pH} 12$. The aqueous phase was extracted with $\mathrm{CH}_{2} \mathrm{Cl}_{2}(2 \times 30 \mathrm{~mL})$, and the combined organic fractions were dried over anhydrous $\mathrm{Na}_{2} \mathrm{SO}_{4}$, filtered, and concentrated under reduced pressure. The crude product was purified by flash column chromatography using ethyl acetate/heptane as eluent to yield $\mathbf{B P}^{-\mathbf{B r}_{2}} \mathbf{( 6 0 \% )}$ as a buff solid. ${ }^{1} \mathrm{H}$ NMR (400 MHz, $\left.\mathrm{CDCl}_{3}\right) \delta 8.52(\mathrm{~d}, 2 \mathrm{H}, \mathrm{J}=4.5 \mathrm{~Hz}), 7.29$ $7.24(\mathrm{~m}, 3 \mathrm{H}), 7.19(\mathrm{dd}, 2 \mathrm{H}, \mathrm{J}=8 \mathrm{~Hz}), 7.15(\mathrm{dd}, 2 \mathrm{H}, \mathrm{J}=4.5 \mathrm{~Hz}) ;{ }^{13} \mathrm{C}$ NMR $\left(100 \mathrm{MHz}, \mathrm{CDCl}_{3}\right) \delta 150.6,148.2,146.4,140.5,130.1$, 129.6, 124.6, 90.2; HRMS (ESI): calcd for $\mathrm{C}_{13} \mathrm{H}_{9} \mathrm{Br}_{2} \mathrm{~N}[\mathrm{M}+\mathrm{H}]^{+}$, 337.9180; found, 337.9212 .

\section{Synthesis of 4,4'-(2-phenyl-2-(pyridin-4-yl)ethene-1,1-} diyl)bis(N,N-diphenylaniline) (TPE). BP- $\mathrm{Br}_{2} \quad(200 \mathrm{mg}, 0.60$ $\mathrm{mmol}$ ) was dissolved in $40 \mathrm{~mL}$ of dioxane:water (4:1). The flask was charged with $\mathrm{Na}_{2} \mathrm{CO}_{3}(320 \mathrm{mg}, 3.00 \mathrm{mmol}), \mathrm{Pd}(\mathrm{OAc})_{2}(18$ $\mathrm{mg}, 0.08 \mathrm{mmol}), \mathrm{PPh}_{3}(80 \mathrm{mg}, 0.30 \mathrm{mmol})$, and 4(diphenylamino)phenylboronic acid $(867 \mathrm{mg}, 3.00 \mathrm{mmol})$. The reaction mixture was heated to reflux for $12 \mathrm{~h}$. After cooling to $\mathrm{RT}$, the reaction mixture was extracted with ethyl acetate $(3 \times$ $50 \mathrm{~mL}$ ) and the combined organic fractions were dried over anhydrous $\mathrm{Na}_{2} \mathrm{SO}_{4}$, filtered, and concentrated under reduced pressure. The crude product was purified by flash column chromatography using ethyl acetate/heptane as eluent to yield the targeted TPE as a yellow solid (50\%). ${ }^{1} \mathrm{H}$ NMR $(400 \mathrm{MHz}$, $\left.\mathrm{CDCl}_{3}\right) \delta 8.29(\mathrm{dd}, 2 \mathrm{H}, \mathrm{J}=4.5 \mathrm{~Hz}), 7.19-7.13(\mathrm{~m}, 8 \mathrm{H}), 7.08(\mathrm{~d}, 3 \mathrm{H}$, $\mathrm{J}=1.6 \mathrm{~Hz}), 6.99-6.90(\mathrm{~m}, 14 \mathrm{H}), 6.88(\mathrm{dd}, 2 \mathrm{H}, \mathrm{J}=2.1 \mathrm{~Hz}), 6.85-$ $6.80(\mathrm{~m}, 4 \mathrm{H}), 6.76-6.70(\mathrm{~m}, 4 \mathrm{H}) ;{ }^{13} \mathrm{C} \mathrm{NMR}\left(100 \mathrm{MHz}, \mathrm{CDCl}_{3}\right)$ $\delta 152.3,149.2,147.5,147.4,146.9,146.6,143.3,142.9,136.6$, $136.2,132.2,131.4,129.3,129.2,127.9,126.8,126.1,124.6$, 124.5, 123.1, 122.9, 122.3; HRMS (ESI): calcd for $\mathrm{C}_{49} \mathrm{H}_{37} \mathrm{~N}_{3}$ $[\mathrm{M}+\mathrm{H}]+, 668.2987$; found, 668.3060.

Synthesis of 4-(2,2-bis(4-(diphenylamino)phenyl)-1phenylvinyl)-1-octylpyridin-1-ium iodide (TPE-I). The above synthesized TPE (100 mg, $0.15 \mathrm{mmol}$ ) was dissolved in dry acetonitrile $(20 \mathrm{~mL})$ and stirred at room temperature. 1iodooctane ( $70 \mathrm{mg}, 0.30 \mathrm{mmol}$ ) was added slowly to the stirring solution under nitrogen atmosphere. The reaction was then allowed to reflux for $16 \mathrm{~h}$ to get the complete alkylation. The solvent was evaporated under reduced pressure and the residue was purified by flash column chromatography using DCM-methanol as eluent to give TPE-I as orange solid (85\%). ${ }^{1} \mathrm{H}$ NMR (400 MHz, $\left.\mathrm{CDCl}_{3}\right) \delta 8.79(\mathrm{~d}, 2 \mathrm{H}, \mathrm{J}=6.5 \mathrm{~Hz}), 7.35(\mathrm{~d}, 2 \mathrm{H}, \mathrm{J}=$ $6.8 \mathrm{~Hz}), 7.26(\mathrm{t}, 4 \mathrm{H}, \mathrm{J}=7.8 \mathrm{~Hz}), 7.17(\mathrm{~d}, 6 \mathrm{H}, \mathrm{J}=7.4 \mathrm{~Hz}), 7.08(\mathrm{~d}$, $4 \mathrm{H}, \mathrm{J}=7.6 \mathrm{~Hz}), 7.03(\mathrm{~d}, 2 \mathrm{H}, \mathrm{J}=7.28 \mathrm{~Hz}), 6.98-6.96(\mathrm{~m}, 9 \mathrm{H}), 6.84$ $(\mathrm{d}, 2 \mathrm{H}, \mathrm{J}=8.8 \mathrm{~Hz}), 6.78-6.75(\mathrm{~m}, 4 \mathrm{H}), 6.68(\mathrm{~d}, 2 \mathrm{H}, \mathrm{J}=8.8 \mathrm{~Hz}), 4.72$ $(\mathrm{t}, 2 \mathrm{H}, \mathrm{J}=7.4 \mathrm{~Hz}), 1.91(\mathrm{t}, 2 \mathrm{H}, \mathrm{J}=6.9 \mathrm{~Hz}), 1.28-1.15(\mathrm{~m}, 10 \mathrm{H})$, $0.80-0.76(\mathrm{t}, 3 \mathrm{H}, \mathrm{J}=6.6 \mathrm{~Hz}) ;{ }^{13} \mathrm{C}$ NMR $\left(100 \mathrm{MHz}^{\mathrm{C} C \mathrm{CD}_{3}}\right) \delta 146.9$, $146.6,132.9,132.7,131.6,129.6,129.4,129.2,128.9,127.9$, $125.7,125.2,124.3,123.8,120.8,31.7,28.9,25.9,22.6,14.1$; HRMS (ESI-positive mode): calcd for $\mathrm{C}_{57} \mathrm{H}_{54} \mathrm{~N}_{3}{ }^{+}[\mathrm{M}]^{+}, 780.4317$; found, 780.4339 .

General procedure for the exchange of counterions in TPE-I. The synthesized TPE-I $(20 \mathrm{mg}, 0.025 \mathrm{mmol})$ and 1.5 equivalents of the corresponding salts ((potassium tetrakis (pentafluorophenyl) borate ethyl etherate (F5), tetrakis[3,5-bis(1,1,1,3,3,3-hexafluoro-2-methoxy-2-propyl)phenyl]borate (F12), potassium hexafluorophosphate $\left(\mathbf{P F}_{6}\right)$ and potassium perchlorate $\left(\mathrm{ClO}_{4}\right)$ ) were mixed in $2 \mathrm{ml}$ of dichloromethane and stirred for 5-10 min until TLC showed complete conversion. Product was purified by column chromatography using DCMmethanol as eluent. After evaporation of solvents, the pure product with different counterions were obtained in quantitative yields.

Preparation of fluorescent NPs. The TPE-I was dissolved at 1 $\mathrm{mM}$ in acetonitrile and used as stock solution. $10 \mu \mathrm{L}$ from the stock solution was added quickly under vigorous stirring to 1.9 $\mathrm{mL}$ of Milli-Q water (Millipore). Then to the obtained solution 10 -fold excess of the corresponding salt solution $(100 \mu \mathrm{L}$ of 1 $\mathrm{mM}$ stock solution) of different counterions was added quickly under stirring using a micropipette, the resultant NPs were directly used for DLS and spectroscopic measurements.

For the polymeric NPs, stock solutions of the polymer (PMMA-MA) in acetonitrile were prepared at a concentration of $1 \mathrm{mg} / \mathrm{mL}$ containing varying amounts of TPE-F12, TPE-F5, TPE$\mathrm{PF}_{6}$ and $\mathrm{TPE}_{-} \mathrm{ClO}_{4}$ depending on the amount of loading. Further, $50 \mu \mathrm{l}$ of the polymer solutions were added quickly to $450 \mu \mathrm{l}$ of $20 \mathrm{mM}$ phosphate buffer using a micropipette and under shaking (Thermomixer comfort, Eppendorf, 1,000 r.p.m.) at 21 ${ }^{\circ} \mathrm{C}$. The obtained nanoparticles suspension was further diluted five-fold with phosphate buffer $20 \mathrm{mM}$, pH 7.4, which were used for the measurements. 
TEM measurements. Carbon-coated copper-rhodium electron microscopy grids with a 300 mesh (Euromedex) were surfacetreated with a glow discharge in amylamine atmosphere $(0.45$ mbar, 4-5 mA, $40 \mathrm{~s}$ ) in an Elmo glow discharge system (Cordouan Technologies). Then, $5 \mu$ I of the TPE polymeric NPs were deposited onto the grids and left for $1 \mathrm{~min}$. The grids were washed with milli $Q$ water followed by stained with a $2 \%$ uranyl acetate solution for $1 \mathrm{~min}$. The measurements were taken on a Philips CM120 transmission electron microscope equipped with a LaB6 filament and operating at $100 \mathrm{kV}$. Areas of interest of all the TPE polymeric NPs were recorded at different magnifications on a Peltier cooled CCD camera (Model 794, Gatan). The obtained raw images were analyzed using Fiji software.

Single-particle fluorescence measurements. For single-particle fluorescence microscopy measurements, the NPs were immobilized on glass surfaces which are initially treated with polyethylenimine (PEI), as described before. ${ }^{75}$ The solutions of TPE polymeric NPs were diluted to 2000 times and $350 \mu$ of the same per $\mathrm{cm}^{2}$ were then brought into contact with the PEIcovered glass for $15 \mathrm{~min}$. Appropriate quantum dots (QD705, $0.5 \mathrm{pM}$ ) were also introduced to the glass surfaces similarly as control. The surfaces were rinsed extensively with water and left in milli-Q water during microscopy experiments.

Single-particle measurements were performed in the widefield epi-fluorescence mode using Nikon Ti-E inverted microscope with a 100x objective (Apo TIRF, oil, NA 1.49, Nikon). The excitation was provided by light emitting diodes (LED, SpectraX, Lumencor) at $470 \mathrm{~nm}\left(7.6 \mathrm{~W} \mathrm{~cm}^{-2}\right.$ power density). The presented images were an average of the first 20 frames (recorded at 200 ms integration time), whereas the time lapse data were recorded for $10 \mathrm{~s}$ with $100 \mathrm{~ms}$ integration time. The single-particle analysis was performed using Fiji software.

Cell culture and imaging. HeLa cells (ATCC ${ }^{\circledR} \mathrm{CCL}-2^{\text {TM }}$ ) were grown in DMEM (without phenol red) at $37{ }^{\circ} \mathrm{C}$ under a humidified atmosphere containing 5\% CO2, supplemented with $10 \%$ heat inactivated fetal bovine serum (FBS), L-Glutamine, Penicillin and Streptomycin. Further, cells were seeded onto an ibidi treated glass petridish and incubated for 24 hours. For imaging, the culture medium was removed and the attached cells were washed two times with PBS and one time with OptiMEM (Gibco-Invitrogen). Then, a freshly prepared solution of TPE polymeric NPs (at 30 -fold dilution of the original formulation) in Opti-MEM was added to the cells and incubated for $3 \mathrm{~h}$. Cell membrane staining was carried out with F2N12SM ${ }^{87}$ ( $50 \mathrm{nM}$ ) for $10 \mathrm{~min}$ at RT before the microscopic measurements. Fluorescence imaging was performed in the spinning disk mode using X-Light CREST module in Nikon Ti-E inverted microscope with a $60 x$ objective, using $488 \mathrm{~nm}$ laser irradiation with a 670$740 \mathrm{~nm}$ detection range for imaging TPE-NPs and $405 \mathrm{~nm}$ excitation with a $450-500 \mathrm{~nm}$ emission range for imaging the membrane marker F2N12SM. The photostability measurements in cells were performed as in the case of single- particle microscope in the wide-field mode using $470 \mathrm{~nm}$ LED excitation at $2.5 \mathrm{~W} \mathrm{~cm}^{-2}$ power density.

Cytotoxicity. Cytotoxicity of the TPE NPs was quantified by the MTT (3-(4,5-dimethylthiazol-2-yl)-2,5-diphenyltetrazolium bromide) assay. The HeLa cells were seeded in a 96-well plate at a density of 1000 cells per well and left to adhere for $24 \mathrm{~h}$ in Dulbecco's Modified Eagle Medium (Gibco LifetechnologiesDMEM) complemented with $10 \%$ fetal bovine serum, were incubated in a $5 \% \mathrm{CO}_{2}$ incubator at $37^{\circ} \mathrm{C}$. After removal of the medium, $100 \mu \mathrm{L}$ DMEM containing $70 \mathrm{nM}, 140 \mathrm{nM}, 210 \mathrm{nM}$ and $700 \mathrm{nM}$ of TPE NPs (TPE-F12, TPE-F5 or TPE-PF6) was added to the cells and incubated for $24 \mathrm{~h}$ at $37^{\circ} \mathrm{C}(5 \% \mathrm{CO} 2)$. As control, for each 96-well plate, the cells were incubated with DMEM or with triton $\mathrm{X}-100(0.1 \%)$ as a positive control of cytotoxicity. After $24 \mathrm{~h}$ of the incubation, the medium was replaced by 100 $\mu \mathrm{L}$ of a mixture containing DMEM and MTT solution (diluted in PBS) and the cells were incubated for $4 \mathrm{~h}$ at $37^{\circ} \mathrm{C}$. Then, $75 \mu \mathrm{L}$ of the mixture was replaced by $50 \mu \mathrm{L}$ of DMSO (100\%) and the plate was gently shaken for $15 \mathrm{~min}$ at $\mathrm{rt}$ in order to dissolve the insoluble purple formazan. The absorbance at $540 \mathrm{~nm}$ was measured (absorbance of the NPs at $540 \mathrm{~nm}$ was taken into account). Each concentration of dye was tested in sextuplicate.

\section{Conclusions}

Aggregation-induced emission dyes have been successfully applied for preparation fluorescent materials, but they have been rarely used for encapsulation into nanoparticles build of hydrophobic polymers, such as derivatives of poly(methyl methacrylate) (e.g. PMMA-MA). Here, we combined AIE with recently developed approach of bulky hydrophobic counterions for preparation of bight dye-loaded polymeric nanoparticles. To this end, we synthesized TPE-based cationic AlEgen and investigated its AIE behaviour in solvents as a function of counterion. Although all studied AIEgen salts showed AIE behaviour in solvents, those containing bulky fluorinated tetraphenyl borates produced $\sim 50 \mathrm{~nm}$ red shift in absorption and emission, the latter reaching NIR region. Moreover, only dye salts with the bulky counterions (TPE-F5 and TPE-F12) produced small dye-loaded polymeric NPs, around $50 \mathrm{~nm}$ diameter, emitting in NIR region ( $700 \mathrm{~nm})$, while the salts with small inorganic anions (TPE-ClO4 and TPE-PF6) results in large aggregates with emission in far red $(\sim 650 \mathrm{~nm})$. The singleparticle microscopy revealed that the brightness of the obtained NPs was $\sim 6$-fold higher than that of quantum dots of similar emission color and size (QD705 at $470 \mathrm{~nm}$ excitation). These results were in agreement with the estimated brightness: 2.1-2.7 $\times 10^{7} \mathrm{M}^{-1} \mathrm{~cm}^{-1}$ for our NPs vs $4.2 \times 10^{6} \mathrm{M}^{-1} \mathrm{~cm}^{-1}$ for QD705. Cellular imaging studies suggested efficient internalization of NPs by endocytosis, allowing high quality cellular imaging. By contrast, AlEgens with small inorganic counterions with or without PMMA-MA polymer showed irregular emission of large fluorescent aggregates without clear cellular organization. Finally, AlEgen-loaded polymeric NPs with bulky counterions 
exhibited negligible cytotoxicity, in contrast to those with small inorganic anions, probably due to better encapsulation of the former in the hydrophobic polymer matrix. Thus, the combination of AlEgens with fluorinated tetraphenylborate counterions enables (i) formulation of small dye-loaded NPs based on hydrophobic polymer; (ii) good fluorescence quantum yield of encapsulated AlEgens; (iii) red shifted emission in the NIR region; (iv) low cytotoxicity and compatibility with live-cell imaging. Further work will be needed to address important issues, such as optimizing structure of ionic AlEgen and the counterion to improve fluorescence quantum yields in polymeric NPs as well as better understanding the role of the counterion in the dye organization and potential dye clustering ${ }^{45}$ in the polymer NPs, which will be important for fine tuning their optical properties. Moreover, we believe that our approach of combining AlEgens and bulky counterions will inspire preparation of small and ultrabgiht AlEgen-loaded polymeric NPs for in vitro and in vivo imaging applications.

\section{Conflicts of interest}

There are no conflicts to declare.

\section{Acknowledgements}

N. A. acknowledge Marie Curie post-doctoral research grant (MSCA-H2020-IF, NanoOxySens) by European Union. This work was supported by ERC Consolidator grant BrightSens 648528 . We thank A. Reisch for fruitful discussions and J. Valanciunaite for technical support. The authors also thank C. Ruhlmann and C. Crucifix from the FRISBI platform (ANR-10-INBS-05) for help with electron microscopy.

\section{Notes and references}

1 O. S. Wolfbeis, Chem. Soc. Rev., 2015, 44, 4743.

2 W. P. Dempsey, S. E. Fraser and P. Pantazis, BioEssays, 2014, 34, 351.

3 P. D. Howes, R. Chandrawati, M. M. Stevens, Science 2014, 346,1247390

4 S. Song, Y. Qin, Y. He, Q. Huang, C. Fan and H.-Y. Chen, Chem. Soc. Rev., 2010, 39, 4234.

5 Y. Wang, B. Yan and L. Chen, Chem. Rev., 2013, 113, 1391.

6 D. E. Owens and N. A. Peppas, Int. J. Pharm. 2006, 307, 93.

7 A. E. Nel, L. Mädler, D. Velegol, T. Xia, E. M. V. Hoek, P. Somasundaran, F. Klaessig, V. Castranova and M. Thompson, Nat. Mater. 2009, 8, 543.

8 M. P. Monopoli, C. Aberg, A. Salvati and K. A. Dawson, Nat. Nanotechnol. 2012, 7, 779.

9 Y. Min, M. Akbulut, K. Kristiansen, Y. Golan, J. Israelachvili, Nat. Mater. 2008, 7, 527.

10 X. Michalet, F. F. Pinaud, L. A. Bentolila, J. M. Tsay, S. Doose, J. J. Li, G. Sundaresan, A. M. Wu, S. S. Gambhir and S. Weiss, Science, 2005, 307, 538-544.

11 K. D. Wegner, N. Hildebrandt, N. Chem. Soc. Rev. 2015, 44, $4792-4834$

12 X. Wu, X. He, K. Wang, C. Xie, B. Zhou and Z. Qing, Nanoscale, 2010, 2, 2244

13 X. Wang, S. Xu and W. Xu, Nanoscale, 2011, 3, 4670.
14 D. Genovese, E. Rampazzo, S. Bonacchi, M. Montalti, N. Zaccheronia and Luca Prodi, Nanoscale, 2014, 6, 3022.

15 M. Montalti, L. Prodi, E. Rampazzoa and N. Zaccheroni, Chem. Soc. Rev., 2014, 43, 4243.

16 S. W. Bae, W. Tan and J. I. Hong, Chem. Commun., 2012, 48, 2270.

17 S. Wen, J. Zhou, K. Zheng, A. Bednarkiewicz, X. Liu and D. Jin, Nat. Commun, 2018, 9, 1.

18 U. Stochaj, D. C. R. Burbano, D. R. Cooper, M. Kodihaa and J. A. Capobianco, Nanoscale, 2018, 10, 14464.

19 T. Wu, B. Johnsen, Z. Qin, M. Morimoto, D. Baillie, M. Irie and N. R. Branda, Nanoscale, 2015, 7, 11263.

20 E. M. Chan, Chem. Soc. Rev., 2015, 44, 1653.

21 N. Tomczak, R. Liua and J. G. Vancso, Nanoscale, 2013, 5, 12018.

22 A. R. Clapp, I. L. Medintz, J. M. Mauro, B. R. Fisher, M. G. Bawendi, H. Mattoussi, J. Am. Chem. Soc. 2004, 126, 301.

23 C. Y. Zhang, H. C. Yeh, M. T. Kuroki, T. H. Wang, Nat. Mater. 2005, 4, 826.

24 M. Bottrilla and M. Green, Chem. Commun., 2011, 47, 7039.

25 A. Anas, H. Akita, H. Harashima, T. Itoh, M. Ishikawa and V. Biju, J. Phys. Chem. B, 2008, 112, 10005.

26 S. Prakash, S. Rao and C. Dameron, Biochem. Biophys. Res. Commun., 1998, 244, 198.

27 Z. Hossain and F. Huq, J. Inorg. Biochem., 2002, 90, 85.

28 A. Gnach, T. Lipinski, A. Bednarkiewicz, J. Rybkaab and J. A. Capobianco, Chem. Soc. Rev., 2015, 44, 1561.

29 H.-S. Peng and D. T. Chiu, Chem. Soc. Rev. 2015, 44, 4699.

30 A. Vollrath, S. Schubert and U. S. Schubert, J. Mater. Chem. B, 2013, 1, 1994.

31 K. Lia and B. Liu, Chem. Soc. Rev., 2014, 43, 6570.

32 A. Reisch and A. S. Klymchenko, Small 2016, 12, 1968.

33 A. Kaeser and A. P. H. J. Schenning, Adv. Mater., 2010, 22, 2985.

34 L. Feng, C. Zhu, H. Yuan, L. Liu, F. Lva and S. Wang, Chem. Soc. Rev., 2013, 42, 6620.

35 J. Pecher and S. Mecking, Chem. Rev., 2010, 110, 6260.

36 K. Y. Pu and B. Liu, Adv. Funct. Mater., 2011, 21, 3408.

37 C. Wu and D. T. Chiu Angew. Chem. Int. Ed., 2013, 52, 3086.

38 R. Bouchaala, L. Mercier, B. Andreiuk, Y. Mély, T. Vandamme, N. Anton, J. G. Goetz and A. S. Klymchenko, J Control Release. 2016, 236, 57.

39 V. N. Kilin, H. Anton, N. Anton, E. Steed, J. Vermot, T. F. Vandamme, Y. Mely, A. S. Klymchenko, Biomaterials 2014, 35 4950.

40 E. Genin, Z. Gao, J. A. Varela, J. Daniel, T. Bsaibess, I. Gosse L. Groc, L. Cognet, and M. Blanchard-Desce Adv. Mater., 2014, 26, 2258.

41 S. Fery-Forgues, Nanoscale, 2013, 5, 8428.

42 Y. Hong, J. W. Y. Lam and B. Z. Tang, Chem. Soc. Rev., 2011, 40, 5361.

43 J. Mei, N. L. C. Leung, R. T. K. Kwok, J. W. Y. Lam, B. Z. Tang, Chem. Rev. 2015, 115, 11718.

44 K. Trofymchuk, A. Reisch, P. Didier, F. Fras, P. Gilliot, Y. Mely, and A. S. Klymchenko, Nat. Photonics 2017, 11, 657.

45 A. Reisch, K. Trofymchuk, A. Runser, G. Fleith, M. Rawiso, and A. S. Klymchenko. ACS Appl. Mater. Interfaces, 2017, 9, 43030.

46 A. Wagh, F. Jyoti, S. Mallik, S. Qian, E. Leclerc, B. Law, Small 2013, 9, 2129.

47 B. Andreiuk, A. Reisch, M. Lindecker, G. Follain, N. Peyrieras, J. G. Goetz, and A. S. Klymchenko, Small 2017, 13, 1701582.

48 A. Reisch, A. Runser, Y. Arntz, Y. Mély and A. S. Klymchenko, ACS Nano, 2015, 9, 5104.

49 A. Reisch, D. Heimburger, P. Ernst, A. Runser, P. Didier, D. Dujardin, and A. S. Klymchenko, Adv. Funct. Mater. 2018, 28, 1805157.

50 N. Melnychuk and A. S. Klymchenko, J. Am. Chem. Soc., 2018, 140, 10856. 
51 J. Wu, W. Liu, J. Ge, H. Zhang and P. Wang, Chem. Soc. Rev., 2011, 40, 3483.

52 H. Nie, K. Hu, Y. Cai, Q. Peng, Z. Zhao, R. Hu, J. Chen, S.-J. Su, A. Qin and B. Z. Tang, Mater. Chem. Front., 2017, 1, 1125.

53 J. O. Escobedo, O. Rusin, S. Lim and R. M. Strongin, Curr. Opin. Chem. Biol., 2010, 14, 64.

54 M. Kasha, H. R. Rawls and M. A. El-Bayoumi, Pure Appl. Chem., 1965, 11, 371.

55 F. Würthner, T. E. Kaiser and C. R. Saha-Moller, Angew. Chem., Int. Ed., 2011, 50, 3376.

56 R. Méallet-Renault, A. Hérault, J.-J. Vachon, R. B. Pansu, S. Amigoni-Gerbier, C. Larpent, Photochem. Photobiol. Sci. $2006,5,300$.

57 X. Zhang, Z. J. Chen, F. Wurthner, J. Am. Chem. Soc. 2007, 129, 4886.

58 K. Trofymchuk, A. Reisch, I. Shulov, Y. Mely, and A. S. Klymchenko, Nanoscale 2014, 6, 12934.

59 B. Zhang, H. Soleimaninejad, D. J. Jones, J. M. White, K.P. Ghiggino, T. A. Smith, and W. W. H. Wong, Chem. Mater. 2017, 29, 8395 .

60 J. Luo, Z. Xie, J. W. Y. Lam, L. Cheng, H. Chen, C. Qiu, H. S. Kwok, X. Zhan, Y. Liu, D. Zhu and B. Z. Tang, Chem. Commun., 2001, 1740.

61 Y. N. Hong, J. W. Y. Lam and B. Z. Tang, Chem. Commun., 2009, 4332.

62 M. Wang, D. Zhang, G. Zhang and D. Zhu, Chem. Commun., 2008, 4469.

63 M. Wang, G. Zhang, D. Zhang, D. Zhu and B. Z. Tang, J. Mater. Chem., 2010, 20, 1858.

64 J. Geng, Z. Zhu, W. Qin, L. Ma, Y. Hu, G. G. Gurzadyan, B. Z. Tang and Bin Liu, Nanoscale, 2014, 6, 939.

65 L. Yan, Y. Zhang, B. Xu and W. Tian, Nanoscale, 2016, 8, 2471

66 W. Qin, K. Li, G. Feng, M. Li, Z. Yan, B. Liu, B. Z. Tang, Adv. Funct. Mater. 2014, 24, 635-643.

67 W. X. Xue, G. X. Zhang, D. Q. Zhang and D. B. Zhu, Org. Lett., 2010, 12, 2274.

68 X. Q. Zhang, Z. G. Chi, H. Y. Li, B. J. Xu, X. F. Li, S. W. Liu, Y. Zhang and J. R. Xu, J. Mater. Chem., 2011, 21, 1788.

69 Q. Zhao, K. Li, S. Chen, A. Qin, D. Ding, S. Zhang, Y.Liu, B. Liu, J. Z. Sun and B. Z. Tang, J. Mater. Chem., 2012, 22, 15128.

70 J. Geng, K. Li, W. Qin, L. Ma, G. G. Gurzadyan, B. Z. Tang and B. Liu, Small, 2013, 9, 2012.

71 Y. Yang, F. An, Z. Liu, X. Zhang, M. Zhou, W. Li, X. Hao, C.-S. Lee and $X$. Zhang, Biomaterials, 2012, 33, 7803.

72 W.-C. Wu, C.-Y. Chen, Y. Tian, S.-H. Jang, Y. Hong, Y. Liu, R. Hu, B. Z. Tang, Y.-T. Lee, C. T. Chen, W.-C. Chen and A. K.-Y. Jen, Adv. Funct. Mater., 2010, 20, 1413.

73 X. Yan, M. Remond, Z. Zheng, E. Hoibian, C. Soulage, S. Chambert, C. Andraud, B. Van der Sanden, F. Ganachaud, Y. Bretonnière and J. Bernard, ACS Appl. Mater. Interfaces 2018, 10, 25154

74 J. Geng, K. Li, W. Qin, L. Ma, G. G. Gurzadyan, B. Z. Tang, and B. Liu, Small. 2013, 9, 2012.

75 A. Reisch, P. Didier, L. Richert, S. Oncul, Y. Arntz, Y. Mely and A. S. Klymchenko, Nat. Commun. 2014, 5, 4089.

76 B. Andreiuk, A. Reisch, V. G. Pivovarenko and A. S. Klymchenko, Mater. Chem. Front., 2017, 1, 2309.

77 B. Andreiuk, A. Reisch, E. Bernhardt and A. S. Klymchenko, Chem. Asian J., 2019, 14, 836.

78 X. Gu, X. Zhang, H. Ma, S. Jia, P. Zhang, Y. Zhao, Q. Liu, J. Wang, X. Zheng, J. W. Y. Lam, D. Ding and B. Z. Tang, Adv. Mater. 2018, 30, 1801065.

79 I. Shulov, S. Oncul, A. Reisch, Y.Arntz, M. Collot, Y. Mely and A. S. Klymchenko, Nanoscale, 2015, 7, 18198.

80 D. K. Bwambok, B. El-Zahab, S. K. Challa, M. Li, L. Chandler, G. A. Baker and I. M. Warner, ACS Nano, 2009, 3, 3854.

81 T. Enseki and H. Yao, Chem. Lett., 2012, 41, 1119.
82 M. Soulie, C. Carayon, N. Saffon, S. Blanc and S. F. Forgues, Phys. Chem. Chem. Phys., 2016, 18, 29999.

83 P. E. Kolic, N. Siraj, S. Hamdan, B. P. Regmi and I. M. Warner, J. Phys. Chem. C, 2016, 120, 5155.

84 N. Bhattarai, M. Chen, R. L. Pérez, S. Ravula, P. Chhotaray, S. Hamdan, K. McDonough, S. Tiwari and I. M. Warner, J. Mater. Chem. B, 2018, 6, 5451 .

85 T. Funada, T. Hirose, N. Tamai and H. Yao, Phys. Chem. Chem. Phys., 2015, 17, 11006.

86 Z. R. Grabowski and K. Rotkiewicz, Chem. Rev. 2003, 103 3899.

87 R. Kreder, S. Oncul, O. A. Kucherak, K. A. Pyrshev, E. Real, Y. Mély and A. S. Klymchenko, RSC Adv., 2015, 5, 22899. 